
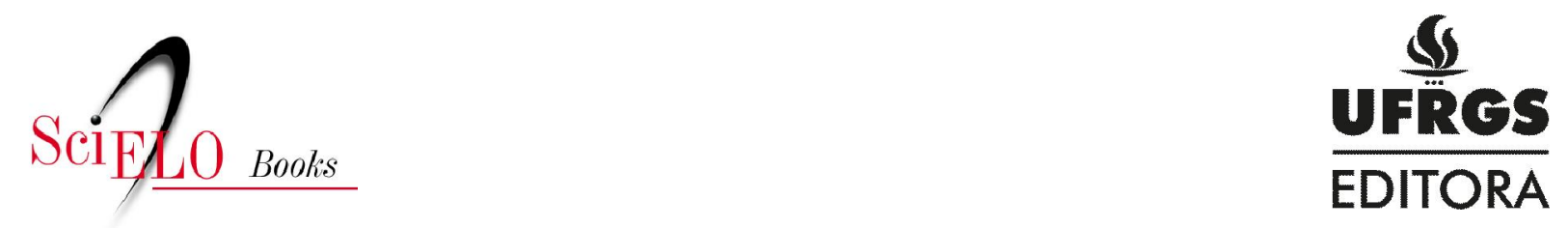

\title{
9 - As sociedades africanas e o colonialismo
}

\author{
Tania Maria Seggiaro Chagastelles
}

\section{SciELO Books / SciELO Livros / SciELO Libros}

CHAGASTELLES, TMS. As sociedades africanas e o colonialismo. In: MACEDO, JR., org. Desvendando a história da África [online]. Porto Alegre: Editora da UFRGS, 2008. Diversidades series, pp. 111-122. ISBN 978-85-386-0383-2. Available from: doi: 10.7476/9788538603832. Also available in ePUB from: http://books.scielo.org/id/yf4cf/epub/macedo-9788538603832.epub.

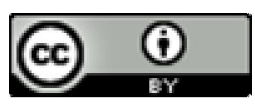

All the contents of this work, except where otherwise noted, is licensed under a Creative Commons Attribution 4.0 International license.

Todo o conteúdo deste trabalho, exceto quando houver ressalva, é publicado sob a licença Creative Commons Atribição 4.0.

Todo el contenido de esta obra, excepto donde se indique lo contrario, está bajo licencia de la licencia $\underline{\text { Creative Commons }}$ Reconocimento 4.0. 


\section{AS SOCIEDADES AFRICANAS E O COLONIALISMO ${ }^{1}$}

\section{Tania Maria Seggiaro Chagastelles}

O desenvolvimento do capitalismo, a partir da primeira expansão européia, na fase quinhentista, levou à incorporação progressiva dos demais continentes ao sistema, de forma subordinada e dependente. As sucessivas hegemonias navais e comerciais - ibérica, holandesa e inglesa - marcaram a presença européia na América, na África e na Ásia.

$\mathrm{Na}$ América, constituíram-se as colônias-padrão da fase mercantilista. A África contribuiu com a mão-de-obra escrava. Com a Ásia, a Europa desenvolveu um lucrativo comércio de especiarias, além de estabelecer alguns enclaves coloniais de excepcional importância para o período seguinte.

No final do século XVIII, uma Era parecia apagar-se, com os movimentos que levaram à independência as colônias americanas e às restrições inglesas ao tráfico de escravos. A base teórica do imperialismo mercantilista - o monopólio - desaparecia diante da nova ideologia burguesa: o liberalismo.

O livre comércio tornou-se a bandeira de uma nova fase imperialista que inaugurava as primeiras décadas do século XIX com a presença britânica e francesa na África. Essa fase constitui o tema da primeira parte deste estudo. A segunda parte aborda a fase imperialista por excelência, a partir das décadas de 1870-80, quando ocorre a partilha propriamente dita do continente. Nessa fase, outras potências, como a Alemanha e a Itália, também procuram estabelecer colônias ou pontos estratégicos na África.

\footnotetext{
${ }^{1}$ Texto publicado originalmente sob o título "As sociedades afro-asiáticas e o colonialismo", na Revista Ciências e Letras (FAPA), n’ 33, em 2005.
} 


\section{A África no Século XIX}

Ainda no século XIX, a Europa não conhece a maior parte do continente africano. Com exceção do norte, banhado pelo Mediterrâneo e berço das antigas civilizações, o deserto do Saara esconde a África tropical que fornece, há séculos, ouro, marfim e, principalmente, escravos.

A região setentrional faz parte, no século XIX, do decadente Império Otomano. Dali, irradiou-se a influência islâmica para as regiões do deserto até os reinos do Sahel e para a costa oriental, da Somália ao Zanzibar. Nessa região, o grande atrativo para os europeus, especialmente britânicos e franceses, é o Egito, por sua localização estratégica na rota para o Oriente.

A África subsaariana permanece fechada em si mesma. Resistira à penetração européia durante séculos, permitindo apenas a ocupação de pequenas partes do seu litoral. A primeira expansão européia, no século XV, legara aos portugueses faixas litorâneas em Angola e Moçambique, ilhas em Cabo Verde, São Tomé e Príncipe. A Espanha ocupara uma faixa ao norte, no Marrocos, e a ilha de Fernando Pó, no Golfo da Guiné; a França, Saint-Louis, no estuário do Senegal; a Inglaterra, Fort James, na foz do Gâmbia; e os holandeses, a colônia do Cabo.

A hegemonia naval e comercial britânica levou-a a apoderar-se dos pontos mais estratégicos para a segurança de suas rotas. É assim que, no início do século, durante as guerras da Revolução Francesa, os ingleses tomam dos holandeses a colônia do Cabo, fundamental para a Rota do Oriente, e assumem uma posição no Gibraltar.

A era da primeira expansão européia, inaugurada pelos ibéricos e muito bem aproveitada pelos britânicos, encerrava-se. A Revolução Industrial, a Revolução Francesa e a independência das colônias americanas se fizeram em função da nova filosofia burguesa - $\mathrm{O}$ liberalismo. Este condena o sistema de exclusividade, consagra o livre-cambismo, a livre concorrência e a liberdade para o trabalho. 
Generaliza-se uma atitude pragmática de liberdade comercial, enquanto o regime de escravidão passa a ter seus dias contados.

A África negra, embora preservasse o seu território da presença branca, fora corroída pela intensidade do tráfico negreiro a partir do século XV - estima-se em mais de 100 milhões a sangria de seus habitantes em apenas quatro séculos.

Os efeitos de tal acontecimento ainda hoje são malcompreendidos e objeto de controvérsias. Não há dúvida, porém, de que os antigos impérios africanos foram desestruturados, provocando o surgimento de novas monarquias, cuja economia passou a basear-se na escravidão para o tráfico.

Ora, no século XIX, as restrições ao tráfico e, por fim, a abolição da escravidão e a ruína do artesanato diante dos produtos manufaturados europeus provocaram nova e dolorosa adaptação. A exportação de produtos agrícolas foi insuficiente para evitar a crise generalizada, manifesta na agudização de antigos antagonismos étnicos e regionais. Esta se manifesta bem antes da penetração oficial das nações européias, pois até meados do século parecia que a era colonial seria definitivamente relegada ao passado. $\mathrm{O}$ anticolonialismo era atitude comum não apenas a estadistas, como à própria opinião pública, que se agitava pela renúncia aos empreendimentos coloniais e em favor do self government (autogoverno). A era do ouro do liberalismo tem na Grã-Bretanha sua principal defensora, especialmente por ser a única nação industrializada e pelo fato de seus mercados não sofrerem séria ameaça de concorrência.

Alguns fatores, no entanto, conjugam-se para facilitar a partilha africana, de vez que proporcionaram o conhecimento do continente aos europeus, tão necessário à sua conquista: a atuação dos missionários e as expedições científicas.

Em 1815, havia apenas 200 missionários católicos fora da Europa. Em 1900, são 6.100. O mesmo acontece com os missionários protestantes, que são 16.000 em 1900. Trata-se de uma nova era de evangelização, inspirada por ideais humanitários e pela cruzada contra a escravidão, que abre rotas de penetração para o interior do continente. 
As expedições científicas são o resultado, por um lado, mais idílico, de uma literatura romântica de evasão que cria mitos - as ilhas, as florestas, os paraísos perdidos - e, de outro, da atuação das sociedades geográficas, tão em moda no século XIX. Desde o final do século XVIII, uma série de expedições foi financiada pela Real Sociedade de Geografia Inglesa. A cada expedição, a publicação dos relatos de viagem encanta o público: Mungo Park, Richard e John Lander, Richard Burton, John Speke e o mais famoso de todos - David Livingstone -, enterrado em 1873 com honras oficiais na abadia de Westminster. O norte-americano Henry Stanley é enviado, pelo New York Herald, à procura de Livingstone, há vários anos desaparecido. Seu livro How I Found Livingstone torna-se best-seller.

Enfim, o aspecto mais pragmático: todo o interior do continente e as bacias dos grandes rios africanos tornaram-se conhecidos dos europeus, facilitando uma penetração que fora, por séculos, evitada.

Ao conhecimento do continente, somam-se novas condições geradas pela Revolução Industrial e pelo progresso científico. O avanço da medicina tem importantes conseqüências para a Europa - sua população mais que dobra no decorrer do século -, mas também para o continente africano, que, por suas doenças tropicais, obtivera a fama de "túmulo do homem branco".

A Europa lança seus excedentes populacionais por todo o planeta, em um movimento migratório sem precedentes, formado especialmente por proletários que não encontram na sua pátria condições de sobrevivência. Por outro lado, na África subsaariana, pela primeira vez, o homem branco - missionários, cientistas, exploradores, comerciantes - sobrevive.

A evolução dos meios de transporte - o navio a vapor, a locomotiva - e dos meios de comunicação, como o telégrafo, completa o quadro favorável à expansão européia no continente africano. A queda no valor das taxas de frete e nas tarifas de transporte facilitou uma maior mobilidade não só para as mercadorias como também para as pessoas, além de elevar o papel das grandes companhias de navega- 
ção, as quais se ligam indissoluvelmente aos interesses coloniais. As estradas de ferro desempenharam papel semelhante e seus trilhos rasgam territórios acompanhados pelos postes telegráficos.

Nessa fase de prelúdio à conquista, ainda antes das décadas finais do século, as formas de penetração posteriores foram relativamente definidas, conforme as preferências européias e, do lado africano, de acordo com as regiões, suas características e reações.

As regiões ocidentais, fornecedoras de escravos aos europeus - Serra Leoa, Costa do Ouro, Nigéria, as regiões do Rio Congo a Angola - foram as que primeiro se adaptaram às novas exigências do capital, ainda na época do livre-cambismo, desenvolvendo uma economia exportadora em substituição ao tráfico negreiro. Ali, o óleo de palma foi o primeiro substituto para a economia baseada no tráfico. O delta do Níger, constituído pelos Oil Rivers (rios de óleo), atraiu os britânicos para a futura Nigéria, apesar da resistência dos iorubas.

As regiões do Rio Senegal atraíram o interesse francês para expansão do seu comércio ao interior, até o alto Níger e o Sudão.

Nas regiões orientais, de grande influência muçulmana, o controle comercial não era europeu, mas árabe, swahili ou indiano. Esses foram gradualmente deslocados, apoderando-se os europeus de suas rotas. Os ingleses, em um primeiro momento, apoiaram o sultanato de Zanzibar na região, rica pelo cultivo e comércio de especiarias, especialmente o cravo.

Convém assinalar que, nessa fase, os interesses europeus na África se achavam representados especialmente por britânicos e franceses, mas também, em menor grau, por italianos e alemães ou pelas duas nações remanescentes da primeira expansão européia, Espanha e Portugal.

Herança da presença holandesa no sul da África, os böers serão motivo de problemas para os colonos ingleses que aportam na colônia do Cabo, levando-os a anexar Natal em 1843. Na grande ilha de Madagascar, os interesses franceses desde o início do século colidem 
freqüentemente com os interesses comerciais dos ingleses, apreensivos com a rota do Cabo para o Oriente.

É no norte da África, contudo, que a presença européia se faz sentir mais forte. Desde a década de 1830, a França enviava colonos para a Argélia, e esse tipo de ocupação caracterizará as zonas do Magreb até a Líbia. Envia colonos à Tunísia, cobiçada pelos comerciantes marselheses; invade o Marrocos em 1844, chocando-se com os espanhóis e retirando-se por insistência e mediação inglesa. Dez anos antes, criara o governo-geral das províncias francesas no norte da África, procurando consolidar a efetiva ocupação da Argélia, que opõe resistência até meados dos anos 1870 .

O Egito, antigo palco das rivalidades franco-britânicas, constituiu, junto com a Tunísia, um dos territórios mais independentes do Império Turco, integrando-se ao sistema capitalista europeu como produtor de algodão. Mehemet Ali e seus sucessores aspiram à modernização das estruturas egípcias, aproximando-se de franceses e ingleses e aproveitando-se da sua rivalidade para contrair empréstimos e promover a construção do Canal de Suez.

O exemplo do Egito e da Tunísia é clássico e precursor de outros casos nos quais a invasão de capitais e empresas européias leva à crise, ao rolamento das dívidas e, como conseqüência de sua insolvência, ao controle internacional imposto pelos credores. A perda da soberania antecede, nesses casos, o domínio efetivo e oficial da potência colonizadora.

\section{A Nova Expansão Imperialista e o Continente Africano}

As profundas transformações que se operam no sistema capitalista a partir de meados do século serão responsáveis por uma radical mudança de atitude por parte dos estadistas e da opinião pública européia, que aderem ao Imperialismo. Vários fatores se conjugam e viabi- 
lizam essas transformações: revolução na técnica, que se reflete na produção industrial, com utilização de novas fontes de energia (petróleo, energia elétrica); a substituição do ferro pelo aço, as novas indústrias siderúrgicas, a produção de bens de capital, a produção em massa, a revolução nos transportes e nos meios de comunicação.

Concomitantemente, novas nações se industrializam e necessitam de mercado. A partir de 1873, já havia uma séria restrição da procura em relação à oferta. Aliás, esse ano inaugura uma longa depressão que durará vinte anos, durante os quais a crise indicou saídas - o monopólio e o protecionismo.

O processo de concentração do capital se faz em meio à crise, entre falências e acordos para sustentar os preços, inimagináveis no ideário liberal. Indústrias e bancos sofrem processo semelhante, e a aproximação de ambos gera o "capitalismo financeiro" - o capital bancário financia os grandes empreendimentos industriais, os quais se protegem formando associações monopolistas - cartéis, trustes, holdings...

As medidas protecionistas são a forma de defesa contra uma concorrência exacerbada entre as nações industrializadas. A Alemanha, a França (decreto de 1880), os Estados Unidos e, por fim, a própria Grã-Bretanha as adotam. O livre-cambismo é definitivamente enterrado, o que inaugura a era de acirramento dos nacionalismos e das rivalidades internacionais.

Ora, o período de crise e de profundas modificações no sistema capitalista coincide exatamente com os anos de maior expansão imperialista e de maior protecionismo.

Delineia-se uma doutrina imperialista, quase que unânime em sua aceitação, pelo menos na última década do século, alimentada pelas rivalidades internacionais, pela xenofobia e por obras pseudocientíficas que exploram a superioridade da raça branca.

A forma intermediária de atuação entre a liberdade comercial do período anterior, especialmente para os ingleses, esteve a cargo de um novo, mas bem conhecido tipo de companhias de carta-pa- 
tente, as quais tiveram curta duração, mas desempenharam importante papel como agentes do poder antes da efetiva entrada em ação dos Estados.

A Royal Niger Company, por exemplo, na sua breve existência de pouco mais de uma década, além de revelar-se muito rentável aos seus acionistas, foi responsável por uma prática que se tornará comum na partilha do continente africano - assinara mais de 400 tratados com os chefes indígenas. Ao tomar posse da região oficialmente, a GrãBretanha indenizou a Cia. em 22 milhões de libras.

Os alemães, por sua vez, na África, adotaram o sistema inglês, por iniciativa dos capitalistas Luderitz e Carl Peters. As maiores rivalidades entre a Deutsch Ostafrika e a British East African ocorrem na África Oriental, antes que acordos definam áreas de influência.

Os franceses continuaram com suas iniciativas individuais na África. A partir dos eixos estabelecidos no período anterior, a França expande-se: ao norte da Argélia para o oeste, chega ao Marrocos; ao leste até a Tunísia, que será anexada em 1881. Às rivalidades iniciais inglesas somam-se, agora, as alemãs e italianas, interessadas, respectivamente, no Marrocos e na Tunísia.

No Egito, onde constrói o Canal de Suez, inaugurado em 1869, a França estabelece um condomínio com a Grã-Bretanha, para administrar as finanças do país (1878). Três anos antes, por iniciativa de Disraelli, os britânicos adquiriram 7/16 das ações do Canal ao governo egípcio. Ali, uma reação nacionalista, liderada pelo coronel Arabi Pachá, é sufocada pelos ingleses, em 1882, bombardeando Alexandria e assumindo o controle da região. Como conseqüência, os ingleses passam a sustentar a política egípcia no Sudão e dali afastam os franceses.

$\mathrm{Na}$ África Ocidental, chocam-se os interesses franceses e ingleses (Royal Niger Company). O plano de Faidherbe, para a França, é unir os pontos extremos da navegação dos rios Senegal e Níger. Dos estabelecimentos costeiros do Senegal e da Guiné, os franceses expandem-se para o interior. Conquistam, ainda, a Costa do Marfim (1893) e o Daomé (1894). 
$\mathrm{Na}$ África Equatorial, a ação é de Savorgnan de Brazza, que funda Brazzaville (1881) na margem direita do Rio Congo. O Estado francês ratifica os tratados por ele firmados com os chefes nativos, estabelecendo um controle cada vez mais formal nas regiões de seu interesse. Aqui, as rivalidades acontecem entre Portugal, Alemanha e, especialmente, um novo personagem, de vital importância para o processo de partilha do continente - Leopoldo II, da Bélgica.

O soberano belga, interessado na região do Rio Congo para seus investimentos particulares, convocara, em 1876, a Conferência Geográfica de Bruxelas, criando uma Associação Internacional Africana. Em nome desta é contratado Henry Morton Stanley para a exploração das regiões do curso superior do grande rio, o que leva à criação do Comitê de Estudos do Alto Congo, o qual será transformado, em 1879, na Associação Internacional do Congo.

As rivalidades na região levaram à realização, entre 1884-85, da Conferência de Berlim, marco histórico do imperialismo contemporâneo. Sob o disfarce de objetivos humanitários, a conferência reúne vários países europeus, com maior ou menor interesse pelo continente africano, aos quais se unem o Império Turco e os Estados Unidos da América. Nenhuma ação independente africana foi convidada a participar dos assuntos que diziam respeito, diretamente, aos seus territórios.

Invocando Deus no seu primeiro parágrafo, o documento que resultou da Conferência pouco cuidou dos objetivos humanitários iniciais, mas estabeleceu "regras" a serem observadas pelas potências signatárias para apropriação "legal" dos territórios africanos. Esta passaria, em primeiro lugar, pela ocupação efetiva do território e, logo após, pela comunicação às demais potências e sua ratificação.

O Estado Livre do Congo foi reconhecido pelos participantes da Conferência e Leopoldo, aclamado seu chefe. Portugal mantinha um pequeno enclave na região - Cabinda -, enquanto a França obtinha como "esfera de influência" a margem direita do Congo.

Reconhecidas foram, ainda, esferas de influência da Alemanha, tanto na costa ocidental como na oriental da África, onde logo esta- 
belecerá suas colônias - Togo, Camarões, a África Oriental Alemã e o Sudoeste Africano.

A Inglaterra teve seus interesses reconhecidos nos Oil Rivers do delta do Níger e, principalmente, o domínio absoluto da África Meridional.

Após definir suas áreas de influência assinando tratados com dirigentes africanos, a contestação possível dessas áreas era contornada através de acordos ou tratados que as potências européias realizavam entre si. Estes liquidaram com as rivalidades anteriores e definiram as esferas de influência metropolitanas e o mapa africano até a $1^{\text {a }}$ Guerra Mundial.

As últimas rivalidades entre franceses e alemães no Marrocos foram resolvidas em 1912, e a França estabeleceu um protetorado sobre o país. A Itália, que já ocupara parte da Eritréia e da Somália, sofre uma espetacular derrota, em 1896, quando tentava a conquista da Etiópia. Em 1911, a região da atual Líbia torna-se uma colônia italiana. Portugal mantém Angola e Moçambique, enquanto o Congo torna-se propriedade do governo belga.

Neste último capítulo da partilha, ao lado dos tratados entre europeus e africanos, que muitas vezes resultaram em fraude imposta pelos primeiros, registra-se o fato de que, em boa parte dos casos, a conquista se efetivou militarmente, o que pressupõe uma resistência dos povos africanos à perda de sua soberania.

Um espetacular desenvolvimento da indústria de armamentos deu incomparável superioridade militar aos europeus. Isso ocorreria no exato momento em que o imperialismo ganhava força. As metralhadoras - a Maxim e a Gatling - serão decisivas para a conquista militar européia. A resistência, por outro lado, deu lugar a lutas anticoloniais célebres, como a Bilundu, em Angola, a Maji-Maji, na África Oriental Alemã, ou a Hut Tax War, na Serra Leoa.

A França, a partir dos anos 1880, põe fim, pela força das armas, a encarniçadas resistências, como a de Samori Touré, Ahmadu, LatDior ou Rabah de Sennar. Quase todos combateram, na defesa dos seus territórios, até a morte. 
Os ingleses, na África Ocidental, só conseguiram vencer a resistência dos achântis em 1901. Na África Oriental, Uganda e Quênia inspiraram o recurso militar, mas foi a reconquista do Sudão, em 1898, o episódio mais sangrento - mais de 20.000 sudaneses morreram em combate.

A África Meridional representa não só o exemplo de uma grande resistência negra - a Zulu -, mas também um dos poucos casos em que brancos chegaram a guerrear entre si: ingleses e böers.

A rivalidade entre ingleses e böers aumentou com a descoberta de ouro e diamantes na região. Os ingleses fizeram grandes inversões de capital, o que resultou em uma demanda maciça de mão-de-obra negra e no surgimento de uma rica oligarquia local, da qual será originário Cecil Rhodes. Este fundou e administrou a Gold Fields of South Africa, para explorar o ouro, e a De Beers Consolidated Mines, para exploração de diamantes. Detentor dos direitos da Companhia Britânica da África do Sul, obteve os poderes que lhe permitiram a anexação de vários territórios.

A guerra anglo-böer resultou em perda momentânea para estes últimos, mas, em 1909, foi criada a União Sul-Africana, que irá reconhecer duas línguas oficiais: a inglesa e a africander (böer). A preponderância política böer se firmará no período entre guerras, moldando uma sociedade que terá como característica a extrema segregação dos grupos nativos no Apartheid.

\section{Referências}

ARRIGHI, Giovanni; SILVER, Beverly J. Caos e governabilidade no moderno sistema mundial. Rio de Janeiro: Contraponto / Ed. UFRGS, 2001.

BOAHEN, A. Adu (Coord.). História geral da África. São Paulo: Ed. Ática/ UNESCO, 1991. Volume 7 - A África sob dominação colonial, 1880-1935.

DAVIDSON, Basil. Os africanos - Uma introdução à sua história cultural. Lisboa: Edições 70, 1969.

FERRO, Marc. A manipulação da História no ensino e nos meios de comunicação. São Paulo: IBRASA, 1983. 
FIELDHOUSE, David K. Los impérios coloniales desde el siglo XVIII. Madrid: Siglo XXI, 1974.

KI-ZERBO, Joseph. História da África negra. Portugal: Ed. Europa, [sd.].

LÊNIN, V. I. O Imperialismo, fase superior do capitalismo. In: Lênin, obras Escolbidas. São Paulo: Alfa-Ômega, 1979. Volume 1.

MACKENZIE, J. M. A partilha da Africa 1880-1900. São Paulo: Ed. Ática, 1994. MIÉGE, Jean-Louis. Expansión europea y descolonización. De 1870 a nuestros dias. Barcelona: Labor, 1980.

RODRIGUES, João Carlos. Pequena história da Africa negra. São Paulo: Ed. Globo, 1990.

SCHNERB, Robert. O século XIX. In: História geral das civilizações. São Paulo: Difusão Européia do Livro, 1969. Volume VI. 